\title{
Combined Effects of Extracorporeal Shockwave Therapy and Integrated Neuromuscular Inhibition on Myofascial Trigger Points of Upper
Trapezius: A Randomized Controlled Trial
}

\author{
Dina Al-Amir Mohamed, $\mathrm{MD}^{1}$, Ragia Mohamed Kamal, $\mathrm{MD}, \mathrm{PhD}^{2}$,
} Manal Mohamed Gaber, $\mathrm{MD}, \mathrm{PhD}^{3}$, Yasser M. Aneis, $\mathrm{MD}, \mathrm{PhD}^{2}$

\author{
${ }^{1}$ Department of Basic Science, Faculty of Physical Therapy, Beni-Suef University, Beni-Suef; \\ ${ }^{2}$ Department of Basic Science, Faculty of Physical Therapy, Cairo University, Giza; \\ ${ }^{3}$ Department of Neurophysiology, Faculty of Medicine, Beni-Suef University, Beni-Suef, Egypt
}

\begin{abstract}
Objective To investigate the combined effect of extracorporeal shockwave therapy (ESWT) and integrated neuromuscular inhibition (INI) on myofascial trigger points in the upper trapezius.

Methods Sixty subjects aged 18-24 years old with active myofascial trigger points in the upper trapezius were studied. Participants were assigned randomly to either group A who received ESWT one session/week, group B who received INI three sessions/week, or group C who received ESWT in addition to INI. All groups completed 4 weeks of intervention. The following main outcome measures were evaluated at baseline and after 4 weeks of intervention: pain intensity, functional disability, pressure pain threshold (PPT), sympathetic skin response (SSR), and neuromuscular junction response (NMJR).

Results Within-group analysis revealed a significant decline in visual analog scale (VAS), Arabic neck disability index (ANDI), and NMJR and incline in PPT and SSR latency post-intervention $(\mathrm{p}<0.001)$. Multiple comparison analysis showed a substantial difference between the groups, while the major changes favored group $\mathrm{C}(\mathrm{p}<0.05)$. Conclusion Combined treatment with ESWT and INI for treating myofascial trigger points in the upper trapezius is more effective than using only one of the two approaches in terms of clinical, functional, and neurophysiological aspects.
\end{abstract}

Keywords Myofascial trigger point, Upper trapezius, Neurophysiological assessment, Extracorporeal shockwave therapy, Integrated neuromuscular inhibition

Received January 26, 2021; Revised March 27, 2021; Accepted April 30, 2021; Published online August 30, 2021

Corresponding author: Dina Al-Amir Mohamed

Department of Basic Science, Faculty of Physical Therapy, Beni-Suef University, East campus, New Beni-Suef city 62517, Beni-Suef, Egypt. Tel: $+20-$ 1229370053, Fax: +20-82-2333367, E-mail: dinaalamir@pt.bsu.edu.eg

ORCID: Dina Al-Amir Mohamed (https://orcid.org/0000-0002-5787-5815); Ragia Mohamed Kamal (https://orcid.org/0000-0001-6996-6469); Manal Mohamed Gaber (https://orcid.org/0000-0002-6608-2710); Yasser M. Aneis (https://orcid.org/0000-0001-6779-5985).

(c) This is an open-access article distributed under the terms of the Creative Commons Attribution Non-Commercial License (http://creativecommons.org/ licenses/by-nc/4.0) which permits unrestricted noncommercial use, distribution, and reproduction in any medium, provided the original work is properly cited. Copyright $\odot 2021$ by Korean Academy of Rehabilitation Medicine 


\section{INTRODUCTION}

Non-specific neck pain represents a serious economic burden that heavily impacts the health system and can lead to severe dysfunction [1]. The myofascial trigger points (MTrPs) are the main reason behind about $54 \%$ of chronic head and neck pains. Myofascial pain is commonly observed in the neck muscles, particularly in the upper trapezius muscle (34.7\%) [2].

The MTrPs can be set out as hyperexcitable spots in a tight band within the skeletal muscle, which ache upon shortening, elongating, or activating and manifest referred pain $[3,4]$. In general, the pathophysiology of MTrPs is still not well understood. The peripheral mechanism produced by muscle over-activity is a clear reason for development of MTrPs [5,6]. However, changes in the central nervous system and stimulation of the autonomic nervous system are known indicators of long-term muscular stress. Trigger points are commonly found in the neuromuscular junction, where they are expected to cause abnormal activity and biochemical alterations $[7,8]$. Excessive acetylcholine release or acetylcholinesterase deficiency may cause the development of a tight band that results in persistent muscle contraction $[8,9]$.

Several management strategies for MTrPs are available. These range from non-invasive approaches like massage [10], pressure release [11], ischemic compression [12,13], and/or spray and stretch [14] to invasive techniques such as dry needling [13-16], and injections [17]. For example, extracorporeal shockwave therapy (ESWT) is a non-invasive modality commonly used in the management of musculoskeletal disorders [18]. It can affect the inflammatory phase through both the induction of tissue regeneration from stem cells and the decrease of the neural transmitter in the affected region, promoting patient improvement [19]. ESWT may also stimulate the desensitizing effect on the treated area through the depletion of sensory nerve fiber neurotransmitters in addition to enhancing fibroblast proliferation and the tissue healing process $[20,21]$.

Integrated neuromuscular inhibition (INI) has also been proposed to alleviate neck pain, improve cervical range of motion, and eliminate neck dysfunction [22]. INI has been approved as an efficient treatment for MTrPs, allowing the use of the three techniques in a single and coordinated manner [23].
Myofascial pain syndrome (MPS) is the most known chronic pain condition, but there are still no clear evidence-based clinical guidelines for ideal management [24]. In clinical practice, it is unlikely that any intervention can be performed in isolation. Therefore, it is crucial to consider the effects of combined therapies. Randomized controlled trials (RCTs) are lacking in investigating the manual treatment combined with ESWT to manage MTrPs. Hence, this study aimed to examine the combined effects of ESWT and INI on pain intensity, pressure pain threshold (PPT), functional disability, sympathetic skin response (SSR), and neuromuscular junction response (NMJR) among subjects with MTrPs in the upper trapezius. It was hypothesized that the combined implementation of ESWT and INI could offer additional benefits compared to the isolated use of the two approaches.

\section{MATERIALS AND METHODS}

This RCT was conducted at the outpatient clinic to investigate the effects of ESWT and INI, in addition to their combined effects on pain intensity, PPT, SSR, NMJR, and functional disability in subjects with MTrPs in the upper trapezius. The study protocol was approved by Research Ethical Committee of Faculty of Physical Therapy, Cairo University, Giza, Egypt (No. P. T. REC/012/002134) and registered at Pan African Clinical Trial Registry (Registry ID PACTR 20181184486658). This study was conducted between December 2018 and January 2020.

\section{Sample size estimation}

The study sample was estimated using the G*Power analytical program (model 3.1.9.2; Franz Faul, University of Kiel, Germany) (F tests, MANOVA-repetitive interaction, $\alpha=0.05, \beta=0.2$, and large effect size $=0.42$ ). The study sample was calculated according to the main outcome (SSR, NMJR) based on the pilot study and reported that $\mathrm{n}=60$ was a sufficient sample size.

\section{Subjects}

The participants were 60 of the university's undergraduate students ( 46 females and 14 males), ranging in age from 18 to 24 years old. The study methodology and objectives were thoroughly explained to all subjects, who were required to give informed consent for participation. The approving subjects were randomly distributed into 
three groups of similar sizes.

The subjects were chosen to be included in the study after meeting certain inclusion criteria. First, medically competent men and women were included. They studied for 3 hours a day, with sufficient breaks in between. They had chronic MTrPs in the upper trapezius for more than 6 months, given the diagnostic criteria of being a tight band with a palpable nodule and distant pain when subjected to pressure [25]. Meanwhile, subjects with previous neck or shoulder pathology (e.g., fracture, surgery, inflammatory and infectious diseases), cervical disc pathology, systemic disorder, fibromyalgia, or those who underwent physical therapy for at least the previous 3 months were excluded.

Subjects who met the inclusion criteria for the trial were assigned at random to one of the following: group A who received ESWT one session/week, group B who received INI three sessions/week, or group $C$ who received ESWT in addition to INI. All groups completed 4 weeks of intervention.

The randomization procedures were carried out by opening a non-transparent envelope, which was set up by a single individual using random number generation.
Fig. 1 shows a flow diagram of the study.

\section{Clinical assessment}

\section{Pain intensity}

The visual analog scale (VAS) was used to assess pain intensity. A scale of $10 \mathrm{~cm}$ was labeled with " 0 " (zero pain) to "10" (the worst imaginable pain). The subjects were instructed to place a vertical mark on the line to indicate their pain [26].

\section{Pressure pain threshold}

A digital force gauge with a rubber tip (Wagner FDX25 Force Gauge; capacity $25 \times 0.02$ Ibf; Wagner Instruments, Greenwich, CT, USA) was used to measure the active MTrPs tenderness by determining the pressure sensitivity, which was assessed by holding the device tip perpendicular to the MTrPs with the patient in the supine position. Pressure was exerted at $1 \mathrm{~kg} / \mathrm{cm}^{2}$. The pressure was removed once the patient began to feel uncomfortable. This procedure was repeated thrice with a 30 -second interval between each trial. The average value of the analysis was obtained [27]. Earlier research approved the PPT intra-rater (ICC 0.6-0.97) and inter-rater (ICC 0.4-0.98)

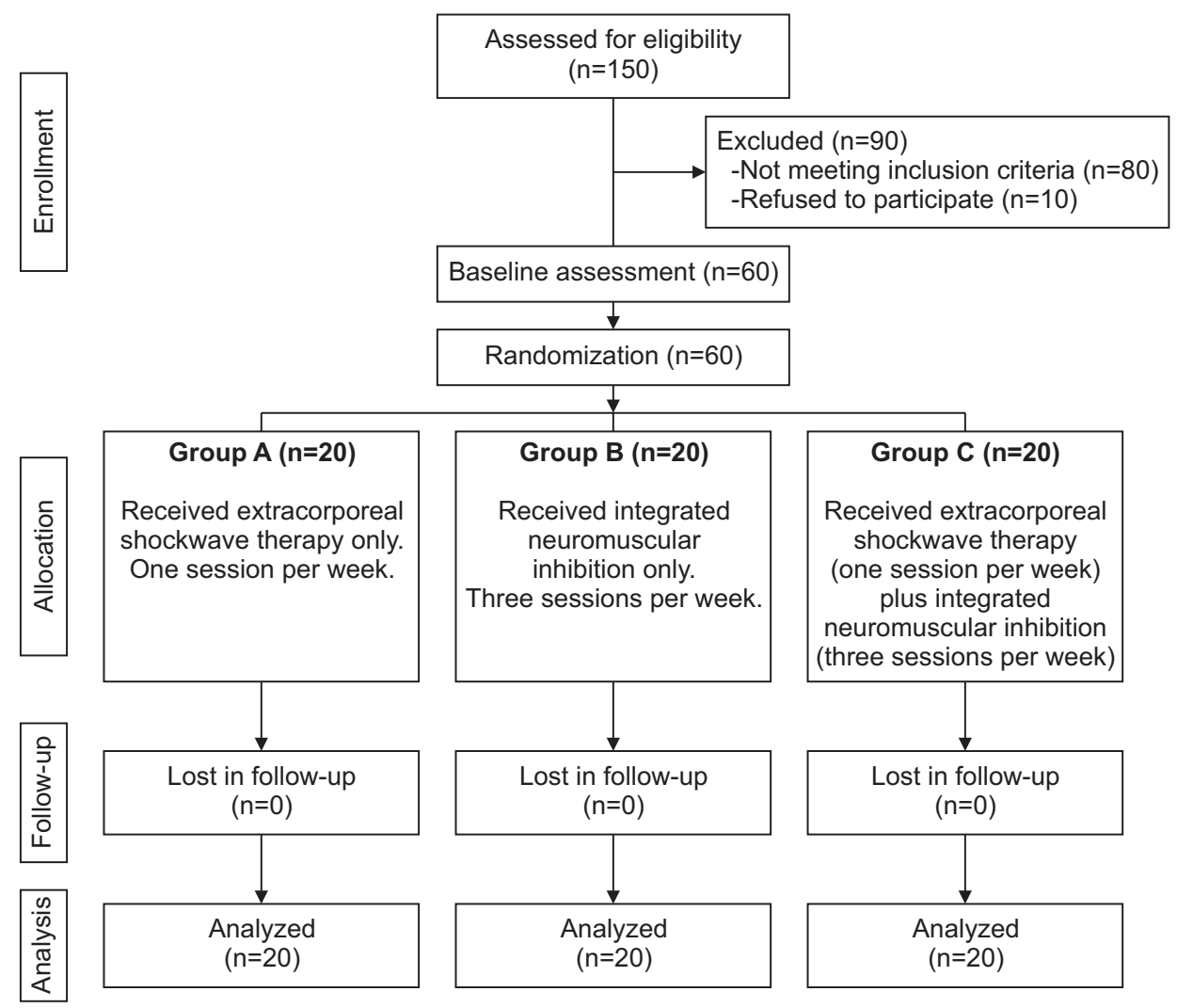

Fig. 1. Flow diagram of participants. 
reliability [28].

\section{Functional disability}

Neck function assessment was performed using the Arabic version of the neck disability index (ANDI). This is a proper tool for assessing neck function [29], composed of 10 categories with six different answers each. The patient chose the best answer to describe his/her state. A score from 0 to 4 represents no disability, 5 to 15 indicates mild disability, 15 to 24 indicates moderate disability, 25 to 34 indicates severe disability, and complete disability is more than 34 [30].

\section{Neurophysiological assessment}

Nihon Kohden electromyography (Neuropack X1 MEB2300K; Nihon Kohden, Tokyo, Japan) was employed to determine the neurophysiological parameters of the SSR and NMJR.

\section{Sympathetic skin response}

The patient was seated in a relaxed position in a silent, semi-dark room, and the temperature was maintained at $24^{\circ} \mathrm{C}$. A single square wave electrical stimulus was used to stimulate the median nerve at the wrist level. The surface and reference electrodes were attached to the palm of the hand. The stimulus was given thrice with a minute of rest in between. The average values of latency and amplitude for the three repetitions were used in the analysis [5].

\section{Neuromuscular junction response}

Repetitive nerve stimulation (RNS) of the spinal accessory motor nerve was used to evaluate NMJR. The stimulator was placed on the posterior boundary of the sternocleidomastoid muscle leveled with the upper boundary of the thyroid cartilage over the spinal accessory motor nerve. The surface recording electrodes were positioned $5 \mathrm{~cm}$ from the spinous process of the 7th cervical vertebra. A series of 10 supramaximal stimuli of $3 \mathrm{~Hz}$ was delivered. The difference in amplitude between the first and fourth compound muscle action potentials (CMAPs) was used to calculate the percentage of decrement or increment changes in CMAP [5].

\section{Intervention}

\section{Integrated neuromuscular inhibition}

INI consists of ischemic compression, strain counter- strain, and muscle energy technique. All subjects were asked to lie in the supine position to decrease their activity in the upper trapezius. This technique was applied three times per week for 4 consecutive weeks [4].

(1) Ischemic compression (IC): Thumb pressure was applied over the trigger point of the upper trapezius. This was continued until the pain decreased. Subsequently, the pressure was reapplied until pain was felt. The application of the aforementioned procedure took 90 seconds and was repeated three to five times [4].

(2) Strain counter-strain (SCS): Mild pressure was placed on the trigger point to the point wherein the patient felt discomfort. This pressure was maintained until the upper trapezius was loosened. To loosen the upper trapezius, the patient was placed in the supine position, while the therapist bent the patient's head in the direction of the affected side. The patient's arm on the same side was also abducted to reduce trigger point pain. Upon achievement of the loosened position, the procedure was continued for 20-30 seconds and repeated thrice [4].

(3) Muscle energy technique (MET): The subjects were asked to raise the affected shoulder up and then bend their head sideways to the shoulder at the same time against resistance. This isometric contraction was maintained for 7 to 10 seconds. The therapist then stretched the affected upper trapezius by bending the head to the opposite side and rotating it to the same side. The stretch was maintained for 30 seconds. This technique was repeated three to five times [4].

\section{Extracorporeal shockwave therapy}

The patient was instructed to lie in the supine position to reduce upper trapezius activity. Four sessions of ESWT were performed using a Gymna ShockMaster 500 device (Gymna, Bilzen, Belgium) adjusted to the following settings: $1.5 \mathrm{bar}, 8 \mathrm{~Hz}$, and 1,000 shocks/trigger point with one session per week [31].

\section{Outcome measures}

VAS, PPT, ANDI, SSR, and NMJR were evaluated both at baseline and after 4 weeks of interventions. 


\section{Data analysis}

Prior to the final analysis, data were tested for the hypotheses of normality and homogeneity of variance, and no violations were reported for any of the dependent variables, as measured by the Shapiro-Wilk test and Levene's test. For all participants, descriptive statistics were assessed at baseline and after 4 weeks of interventions. A mixed model multivariate analysis of variance (MANOVA) was used to estimate variations between and within groups regarding the selected parameters: VAS, PPT, ANDI, SSR, and NMJR pre- and post-interventions. The $\mathrm{F}$ value used was based on Wilks' lambda, and when the MANOVA indicated a significant timexgroup interaction effect, follow-up univariate ANOVAs (two-way mixed model) were executed. The Social Studies Statistical Package (SPSS) version 25 (IBM SPSS, Armonk, NY, USA) was used to perform all statistical tests, and the significance limit was set at $\mathrm{p} \leq 0.05$.

\section{RESULTS}

Before the trial began, 150 participants were screened for eligibility. Seventy subjects fulfilled the inclusion criteria. During the eligibility assessment, 10 subjects were excluded because they declined to participate in the study.

Repeated measures ANOVA showed a substantial main impact for both time (Wilks' $\lambda=0.01, F=553.97, \mathrm{p}<0.001$, $\eta^{2}=0.98$ ) and treatment (Wilks' $\lambda=0.10, \mathrm{~F}=22.55, \mathrm{p}<0.001$, $\eta^{2}=0.68$ ), along with a considerable timextreatment interaction (Wilks' $\lambda=0.06, F=29.74, p<0.001, \eta^{2}=0.73$ ). Follow-up univariate ANOVAs revealed a significant change for VAS ( $\left.F=51.46, p<0.001, \eta^{2}=0.64\right)$, for PPT $(F=99.32$, $\left.\mathrm{p}<0.001, \eta^{2}=0.77\right)$, for ANDI $\left(\mathrm{F}=65.66, \mathrm{p}<0.001, \eta^{2}=0.69\right)$, for SSR latency $\left(\mathrm{F}=41.99, \mathrm{p}<0.001, \eta^{2}=0.59\right)$, and for NMJR $\left(\mathrm{F}=13.03, \mathrm{p}<0.001, \eta^{2}=0.31\right)$. This interaction effect means that the variation between groups on the linear combination of outcomes differs between pre- and post-interventions.

With respect to the demographic and clinical characteristics, there was no significant difference between the pre-intervention groups $(\mathrm{p}>0.05)$ (Table 1). After treatment, there was a statistically significant decline in VAS, ANDI, and NMJR and incline in PPT and SSR latency in the three groups after intervention compared to the baseline $(\mathrm{p}<0.001)$ (Tables 2-5). The results are illustrated in Fig. 2. However, in terms of the differential effects of the three groups on VAS, PPT, ANDI, SSR latency, and NMJR post-intervention, multiple comparison analysis showed a substantial difference between the three groups, while the major changes were in group $\mathrm{C}$, where the mean differences among the groups $\mathrm{A}, \mathrm{B}$, and $\mathrm{C}$ were $(1.65,4.35$, and 4.8) for VAS, $(3.35,9.15$, and 10.2) for ANDI, (-0.68, -1.07, and -2.02) for PPT, (-0.11, -0.22, and -0.43) for SSR latency, and (-7.78, -10.45, and -12.27) for NMJR, respectively (Tables 2-5).

Table 1. Baseline demographic and clinical characteristics of patients

\begin{tabular}{|lcccc}
\hline \multicolumn{1}{c}{ Characteristic } & Group A & Group B & Group C & p-value \\
\hline Age $(\mathrm{yr})$ & $21.2 \pm 1.82$ & $21.5 \pm 2.01$ & $21.3 \pm 1.83$ & 0.87 \\
Weight $(\mathrm{kg})$ & $61.0 \pm 9.38$ & $58.3 \pm 7.51$ & $57.7 \pm 7.81$ & 0.41 \\
\hline Height $(\mathrm{cm})$ & $165.20 \pm 7.41$ & $163.60 \pm 7.92$ & $162.75 \pm 6.24$ & 0.55 \\
BMI $\left(\mathrm{kg} / \mathrm{m}^{2}\right)$ & $22.11 \pm 2.03$ & $21.72 \pm 1.95$ & $21.80 \pm 2.68$ & 0.84 \\
\hline Sex & & & & 0.93 \\
\hline Female & $14(70)$ & $14(70)$ & $16(80)$ & \\
\hline Male & $6(30)$ & $6(30)$ & $4(20)$ & \\
VAS & $6.70 \pm 1.30$ & $6.80 \pm 1.28$ & $6.65 \pm 1.30$ & 0.93 \\
ANDI & $11.5 \pm 2.11$ & $11.7 \pm 1.72$ & $12.7 \pm 2.38$ & 0.16 \\
\hline PPT (kg/cm $)$ & $1.00 \pm 0.19$ & $1.02 \pm 0.20$ & $1.04 \pm 0.21$ & 0.84 \\
\hline SSR (s) & $1.65 \pm 0.25$ & $1.66 \pm 0.28$ & $1.69 \pm 0.27$ & 0.88 \\
\hline CMAP changes (\%) & $-4.75 \pm 1.67$ & $-4.77 \pm 1.80$ & $-4.64 \pm 1.60$ & 0.96 \\
\hline
\end{tabular}

Values are presented as mean \pm standard deviation or number (\%).

BMI, body mass index; VAS, visual analog scale; ANDI, Arabic neck disability index; PPT, pressure pain threshold; SSR, sympathetic skin response; CMAP, compound muscle action potential. 

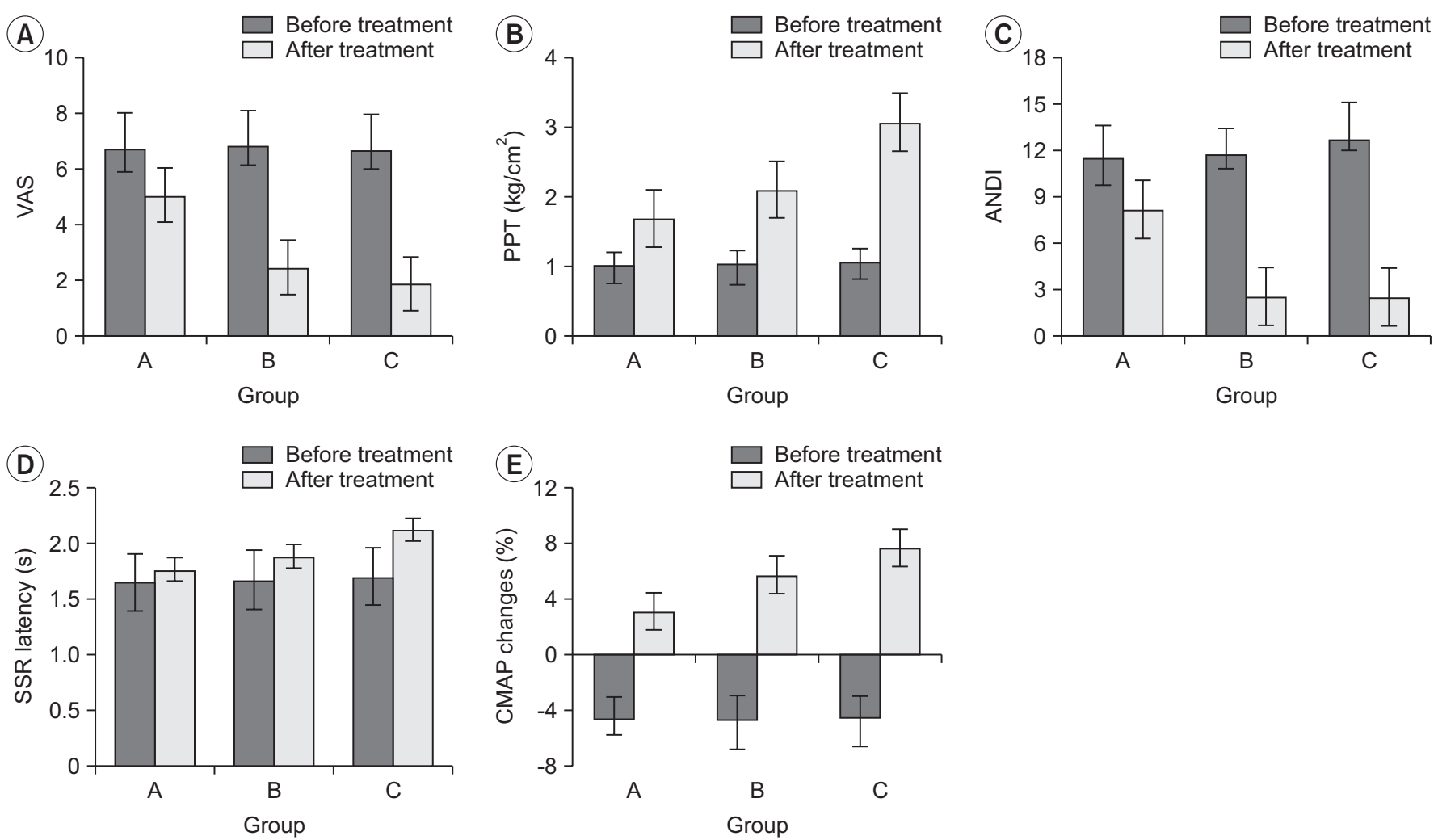

Fig. 2. (A) Pain intensity, (B) pressure pain threshold (PPT), (C) functional disability (ANDI), (D) sympathetic skin response (SSR) latency, and (E) neuromuscular junction response (CMAP) in the three groups pre- and post-intervention. VAS, visual analog scale; ANDI, Arabic neck disability index; CMAP, compound muscle action potential.

Table 2. Mean VAS, ANDI, PPT, SSR latency, and CMAP changes post-intervention

\begin{tabular}{lcccccc}
\hline \multirow{2}{*}{ Characteristic } & \multirow{2}{*}{ Group A } & \multirow{2}{*}{ Group B } & \multirow{2}{*}{ Group C } & \multicolumn{3}{c}{ p-value } \\
\cline { 6 - 8 } & & & & A vs. B & A vs. C & B vs. C \\
\hline VAS & $5.05 \pm 0.82$ & $2.45 \pm 0.68$ & $1.85 \pm 0.67$ & $0.001^{*}$ & $0.001^{*}$ & $0.03^{*}$ \\
ANDI & $8.15 \pm 1.81$ & $2.55 \pm 0.88$ & $2.50 \pm 0.76$ & $0.001^{*}$ & $0.001^{*}$ & 1 \\
PPT ( $\left.\mathrm{kg} / \mathrm{cm}^{2}\right)$ & $1.68 \pm 0.26$ & $2.09 \pm 0.29$ & $3.06 \pm 0.23$ & $0.001^{*}$ & $0.001^{*}$ & $0.001^{*}$ \\
SSR (s) & $1.76 \pm 0.26$ & $1.88 \pm 0.26$ & $2.12 \pm 0.25$ & 0.44 & $0.001^{*}$ & $0.01^{*}$ \\
CMAP changes (\%) & $3.03 \pm 1.08$ & $5.68 \pm 2.14$ & $7.63 \pm 2.04$ & $0.001^{*}$ & $0.001^{*}$ & $0.004^{*}$ \\
\hline
\end{tabular}

Values are presented as mean \pm standard deviation.

VAS, visual analog scale; ANDI, Arabic neck disability index; PPT, pressure pain threshold; SSR, sympathetic skin response; CMAP, compound muscle action potential.

${ }^{*} \mathrm{p} \leq 0.05$.

\section{DISCUSSION}

This randomized controlled trial investigated the effects of ESWT, INI, and the combined effects of both on pain intensity, PPT, functional disability, SSR, and NMJR in subjects with MTrPs in the upper trapezius. The findings showed that the combined treatment of ESWT and INI offered more significant improvements in pain intensity,
PPT, functional disability, SSR, and NMJR as compared to ESWT or INI treatment alone.

Many reports support the findings of this trial, confirming that INI can enhance MTrP-related pain and disability $[22,23,32,33]$, where IC may improve circulation, remove waste products, loosen adhesions, and normalize muscle tone and patient response to pain [32]. However, SCS can achieve its desired effect by reflexively adjust- 
Dina Al-Amir Mohamed, et al.

Table 3. Mean VAS, ANDI, PPT, SSR latency, and CMAP changes pre- and post-intervention for group A

\begin{tabular}{|c|c|c|c|c|c|c|}
\hline \multirow{2}{*}{ Characteristic } & \multirow{2}{*}{ Pre } & \multirow{2}{*}{ Post } & \multirow{2}{*}{$\begin{array}{c}\text { Mean } \\
\text { difference }\end{array}$} & \multicolumn{2}{|c|}{$95 \%$ CI } & \multirow{2}{*}{ p-value } \\
\hline & & & & Lower & Upper & \\
\hline VAS & $6.70 \pm 1.30$ & $5.05 \pm 0.82$ & 1.65 & 1.17 & 2.16 & $0.001^{*}$ \\
\hline ANDI & $11.50 \pm 2.11$ & $8.15 \pm 1.81$ & 3.35 & 2.43 & 4.26 & $0.001^{*}$ \\
\hline PPT $\left(\mathrm{kg} / \mathrm{cm}^{2}\right)$ & $1.00 \pm 0.19$ & $1.68 \pm 0.26$ & -0.68 & -0.81 & -0.53 & $0.001^{*}$ \\
\hline SSR (s) & $1.65 \pm 0.25$ & $1.76 \pm 0.26$ & -0.11 & -0.16 & -0.06 & $0.001^{*}$ \\
\hline CMAP changes (\%) & $-4.75 \pm 1.67$ & $3.03 \pm 1.08$ & -7.78 & -9.04 & -6.53 & $0.001^{*}$ \\
\hline
\end{tabular}

Values are presented as mean \pm standard deviation.

VAS, visual analog scale; ANDI, Arabic neck disability index; PPT, pressure pain threshold; SSR, sympathetic skin response; CMAP, compound muscle action potential.

${ }^{*} \mathrm{p} \leq 0.05$.

Table 4. Mean VAS, ANDI, PPT, SSR latency, and CMAP changes pre-and post-intervention for group B

\begin{tabular}{|c|c|c|c|c|c|c|}
\hline \multirow{2}{*}{ Characteristic } & \multirow{2}{*}{ Pre } & \multirow{2}{*}{ Post } & \multirow{2}{*}{$\begin{array}{c}\text { Mean } \\
\text { difference }\end{array}$} & \multicolumn{2}{|c|}{ 95\% CI } & \multirow{2}{*}{ p-value } \\
\hline & & & & Lower & Upper & \\
\hline VAS & $6.8 \pm 1.28$ & $2.45 \pm 0.68$ & 4.35 & 3.87 & 4.82 & $0.001^{*}$ \\
\hline ANDI & $11.7 \pm 1.72$ & $2.55 \pm 0.88$ & 9.15 & 8.23 & 10.06 & $0.001^{*}$ \\
\hline $\mathrm{PPT}\left(\mathrm{kg} / \mathrm{cm}^{2}\right)$ & $1.02 \pm 0.2$ & $2.09 \pm 0.29$ & -1.07 & -1.21 & -0.93 & $0.001^{*}$ \\
\hline SSR (s) & $1.66 \pm 0.28$ & $1.88 \pm 0.26$ & -0.22 & -0.27 & -0.17 & $0.001^{*}$ \\
\hline CMAP changes (\%) & $-4.77 \pm 1.8$ & $5.68 \pm 2.14$ & -10.45 & -11.70 & -9.20 & $0.001^{*}$ \\
\hline
\end{tabular}

Values are presented as mean \pm standard deviation.

VAS, visual analog scale; ANDI, Arabic neck disability index; PPT, pressure pain threshold; SSR, sympathetic skin response; CMAP, compound muscle action potential.

${ }^{*} \mathrm{p} \leq 0.05$.

Table 5. Mean VAS, ANDI, PPT, SSR latency, and CMAP changes pre-and post-intervention for group C

\begin{tabular}{|c|c|c|c|c|c|c|}
\hline \multirow{2}{*}{ Characteristic } & \multirow{2}{*}{ Pre } & \multirow{2}{*}{ Post } & \multirow{2}{*}{$\begin{array}{c}\text { Mean } \\
\text { difference }\end{array}$} & \multicolumn{2}{|c|}{$95 \%$ CI } & \multirow{2}{*}{ p-value } \\
\hline & & & & Lower & Upper & \\
\hline VAS & $6.65 \pm 1.30$ & $1.85 \pm 0.67$ & 4.80 & 4.32 & 5.27 & $0.001^{*}$ \\
\hline ANDI & $12.70 \pm 2.38$ & $2.50 \pm 0.76$ & 10.20 & 9.28 & 11.11 & $0.001^{*}$ \\
\hline $\mathrm{PPT}\left(\mathrm{kg} / \mathrm{cm}^{2}\right)$ & $1.04 \pm 0.21$ & $3.06 \pm 0.23$ & -2.02 & -2.16 & -1.88 & $0.001^{*}$ \\
\hline SSR (s) & $1.69 \pm 0.27$ & $2.12 \pm 0.25$ & -0.43 & -0.47 & -0.37 & $0.001^{*}$ \\
\hline CMAP changes (\%) & $-4.64 \pm 1.60$ & $7.63 \pm 2.04$ & -12.27 & -13.52 & -11.02 & $0.001^{*}$ \\
\hline
\end{tabular}

Values are presented as mean \pm standard deviation.

VAS, visual analog scale; ANDI, Arabic neck disability index; PPT, pressure pain threshold; SSR, sympathetic skin response; CMAP, compound muscle action potential.

${ }^{*} \mathrm{p} \leq 0.05$.

ing the muscle spindle, which can contribute to normal muscle tone [34]. In contrast, MET has hypoalgesic effects through the inhibitory Golgi tendon reflex, which is activated during isometric contraction and results in reflex muscle relaxation [35].

Similarly, ESWT has been approved as an efficient intervention to relieve pain and disability associated with
MTrPs $[19,36,37]$. ESWT exerts its effects by increasing fibroblast proliferation and tissue healing. It is also able to induce a desensitizing effect on the treated area by depleting sensory nerve fiber neurotransmitters [20,21]. Furthermore, ESWT impacts certain hormones and proteins that control tissue function [36]. The findings of the present trial are aligned with those of many previous 
studies. Ji et al. [37] investigated the impact of ESWT on MTrPs in the upper trapezius and demonstrated its efficacy in reducing pain and increasing pressure sensitivity. In a study comparing the efficacy of ESWT as a noninvasive modality and trigger point injection (TPI) as an invasive modality in the treatment of MTrPs of the quadratus lumborum, Hong et al. [38] found that three sessions of ESWT are more effective than TPI in alleviating pain. Rahbar et al. [39] compared the efficacy of ESWT to conventional treatments such as ultrasound, hot packs, and self-stretches, and they found that ESWT was superior in reducing discomfort. Kamel et al. [40] investigated the impact of ESWT versus regional non-steroidal antiinflammatory medication following neck dissection on pain threshold and intensity for 4 weeks and concluded that ESWT had more significant effects on pain intensity and threshold.

The findings of the present trial indicated an increase in SSR latency, which may be due to the anatomical correlation among afferent pain fibers and sympathetic fibers, given that they are parallel within the central nervous system [41]. The increased SSR latency due to the combined treatment of ESWT and INI may highlight the suppressive influence of these treatments on sympathetic function. The multiple interneuron interface between afferent and efferent fibers in the reflex path may result in the loss or delay of SSR [42].

MTrPs are thought to develop at the neuromuscular junction, where they cause chemical changes and irregular endplate behavior $[7,8]$. Excessive endplate irritation induces an extreme release of acetylcholine. Acetylcholine release or lack of acetylcholinesterase contributes to the development of a taut band that leads to persistent localized muscle fiber contraction [8,9]. Thus, modulating the MTrPs could account for the potential MNJR normalization mechanism.

Our findings are consistent with those of previous studies that confirmed the superiority of the combined treatments. Lytras et al. [33] investigated the impact of INI combined with therapeutic exercise on chronic mechanical neck pain and reported more substantial effects on pain and disability compared to therapeutic exercise alone. Similarly, Alghadir et al. [43] studied the combined effects of IC and MET with conventional therapy in the management of neck pain associated with MTrPs and discovered that the combined treatment was more suc- cessful than either of the two performed alone. Moreover, a pilot study was carried out by Nasb et al. [44] to examine the combined effects of dry cupping and IC in the treatment of MTrPs and neck pain, and it was gathered that combining the two modalities had a greater impact on function and pain threshold.

One of the drawbacks of this study that is worth mentioning is the absence of blinding, wherein all participants were evaluated by the same investigators who implemented the intervention. Additionally, there are no follow-up data on the participants' clinical status, which would help us monitor the long-term effects of our intervention.

Overall, while both ESWT and INI utilized individually improved pain intensity, PPT, functional impairment, SSR, and NMJR, their combined usage led to more marked effects, highlighting the integrated approach as a better option.

\section{CONFLICT OF INTEREST}

No potential conflict of interest relevant to this article was reported.

\section{AUTHOR CONTRIBUTION}

Conceptualization: Al-Amir D, Aneis YM, Kamal RM. Methodology: Al-Amir D, Aneis YM, and Gaber MM. Formal analysis: Al-Amir D, Aneis YM, Gaber MM. Project administration: Kamal RM. Visualisation: Al-Amir D, Aneis YM. Writing-original draft: Al-Amir D, Aneis YM, Gaber MM, Kamal RM. Writing-review and editing: Al-Amir D, Aneis YM, Kamal RM. Approval of the final manuscript: All authors.

\section{REFERENCES}

1. Klein R, Bareis A, Schneider A, Linde K. Straincounterstrain to treat restrictions of the mobility of the cervical spine in patients with neck pain: a shamcontrolled randomized trial. Complement Ther Med 2013;21:1-7.

2. Rachlin ES, Rachlin IS. Myofascial pain and fibromyalgia: trigger point management. St. Louis, MO: Mosby; 2002.

3. Martin-Herrero C, Rodrigues de Souza DP, Alburquer- 
que-Sendin F, Ortega-Santiago R, Fernandez-de-LasPenas C. [Myofascial trigger points, pain, disability and quality of sleep in patients with chronic tensiontype headache: a pilot study]. Rev Neurol 2012;55:1939.

4. Nagrale AV, Glynn P, Joshi A, Ramteke G. The efficacy of an integrated neuromuscular inhibition technique on upper trapezius trigger points in subjects with non-specific neck pain: a randomized controlled trial. J Man Manip Ther 2010;18:37-43.

5. Abbaszadeh-Amirdehi M, Ansari NN, Naghdi S, Olyaei G, Nourbakhsh MR. Neurophysiological and clinical effects of dry needling in patients with upper trapezius myofascial trigger points. J Bodyw Mov Ther 2017;21:48-52.

6. Unalan H, Majlesi J, Aydin FY, Palamar D. Comparison of high-power pain threshold ultrasound therapy with local injection in the treatment of active myofascial trigger points of the upper trapezius muscle. Arch Phys Med Rehabil 2011;92:657-62.

7. Simons DG. Review of enigmatic MTrPs as a common cause of enigmatic musculoskeletal pain and dysfunction. J Electromyogr Kinesiol 2004;14:95-107.

8. Hong CZ, Simons DG. Pathophysiologic and electrophysiologic mechanisms of myofascial trigger points. Arch Phys Med Rehabil 1998;79:863-72.

9. Simons DG, Hong CZ, Simons LS. Endplate potentials are common to midfiber myofacial trigger points. Am J Phys Med Rehabil 2002;81:212-22.

10. Vernon H, Schneider M. Chiropractic management of myofascial trigger points and myofascial pain syndrome: a systematic review of the literature. J Manipulative Physiol Ther 2009;32:14-24.

11. Sarrafzadeh J, Ahmadi A, Yassin M. The effects of pressure release, phonophoresis of hydrocortisone, and ultrasound on upper trapezius latent myofascial trigger point. Arch Phys Med Rehabil 2012;93:72-7.

12. Cagnie B, Dewitte V, Barbe T, Timmermans F, Delrue N, Meeus M. Physiologic effects of dry needling. Curr Pain Headache Rep 2013;17:348.

13. Cagnie B, Castelein B, Pollie F, Steelant L, Verhoeyen $\mathrm{H}$, Cools A. Evidence for the use of ischemic compression and dry needling in the management of trigger points of the upper trapezius in patients with neck pain: a systematic review. Am J Phys Med Rehabil 2015;94:573-83.
14. Hong CZ, Chen YC, Pon CH, Yu J. Immediate effects of various physical medicine modalities on pain threshold of an active myofascial trigger point. J Musculoskelet Pain 1993;1:37-53.

15. Kietrys DM, Palombaro KM, Azzaretto E, Hubler R, Schaller B, Schlussel JM, et al. Effectiveness of dry needling for upper-quarter myofascial pain: a systematic review and meta-analysis. J Orthop Sports Phys Ther 2013;43:620-34.

16. Pecos-Martin D, Montanez-Aguilera FJ, Gallego-Izquierdo T, Urraca-Gesto A, Gomez-Conesa A, Romero-Franco N, et al. Effectiveness of dry needling on the lower trapezius in patients with mechanical neck pain: a randomized controlled trial. Arch Phys Med Rehabil 2015;96:775-81.

17. Kim DH, Yoon DM, Yoon KB. The effects of myofascial trigger point injections on nocturnal calf cramps. J Am Board Fam Med 2015;28:21-7.

18. Ogden JA, Alvarez RG, Levitt R, Marlow M. Shock wave therapy (Orthotripsy) in musculoskeletal disorders. Clin Orthop Relat Res 2001;(387):22-40.

19. Gur A, Koca I, Karagullu H, Altindag O, Madenci E, Tutoglu A, et al. Comparison of the effectiveness of two different extracorporeal shock wave therapy regimens in the treatment of patients with myofascial pain syndrome. Turk J Rheumatol 2014;29:186-93.

20. Berta L, Fazzari A, Ficco AM, Enrica PM, Catalano MG, Frairia R. Extracorporeal shock waves enhance normal fibroblast proliferation in vitro and activate mRNA expression for TGF-betal and for collagen types I and III. Acta Orthop 2009;80:612-7.

21. Ochiai N, Ohtori S, Sasho T, Nakagawa K, Takahashi K, Takahashi N, et al. Extracorporeal shock wave therapy improves motor dysfunction and pain originating from knee osteoarthritis in rats. Osteoarthritis Cartilage 2007;15:1093-6.

22. Sibby GM, Kavitha Vishal S, Narasimman. Effectiveness of integrated neuromuscular inhibitory technique and LASER with stretching in the treatment of upper trapezius trigger points. J Exerc Sci Physiother 2009;5:115-21.

23. Chaitow L, DeLany J. Modern neuromuscular techniques. Edinburgh, UK: Churchill Livingstone; 1996.

24. Fleckenstein J, Zaps D, Ruger LJ, Lehmeyer L, Freiberg F, Lang PM, et al. Discrepancy between prevalence and perceived effectiveness of treatment methods in 
myofascial pain syndrome: results of a cross-sectional, nationwide survey. BMC Musculoskelet Disord 2010;11:32.

25. Gilani MH, Obaid S, Tariq M. Comparison between effectiveness of ischemic compression and muscle energy technique in upper trapezius myofascial trigger points. ISRA Med J 2018;10:230-4.

26. Price DD, McGrath PA, Rafii A, Buckingham B. The validation of visual analogue scales as ratio scale measures for chronic and experimental pain. Pain 1983;17:45-56.

27. Lluch E, Arguisuelas MD, Coloma PS, Palma F, Rey A, Falla D. Effects of deep cervical flexor training on pressure pain thresholds over myofascial trigger points in patients with chronic neck pain. J Manipulative Physiol Ther 2013;36:604-11.

28. Takala EP. Pressure pain threshold on upper trapezius and levator scapulae muscles. Repeatability and relation to subjective symptoms in a working population. Scand J Rehabil Med 1990;22:63-8.

29. Shaheen AA, Omar MT, Vernon H. Cross-cultural adaptation, reliability, and validity of the Arabic version of neck disability index in patients with neck pain. Spine (Phila Pa 1976) 2013;38:E609-15.

30. Childs JD, Cleland JA, Elliott JM, Teyhen DS, Wainner RS, Whitman JM, et al. Neck pain: clinical practice guidelines linked to the International Classification of Functioning, Disability, and Health from the Orthopedic Section of the American Physical Therapy Association. J Orthop Sports Phys Ther 2008;38:A1-A34.

31. Ramon S, Gleitz M, Hernandez L, Romero LD. Update on the efficacy of extracorporeal shockwave treatment for myofascial pain syndrome and fibromyalgia. Int $\mathrm{J}$ Surg 2015;24(Pt B):201-6.

32. Jagad BH, Jagad KB. Effects of ischemic compression on the trigger points in the upper trapezius muscle. Indian J Physiother Occup Ther 2013;7:99-104.

33. Lytras DE, Sykaras EI, Christoulas KI, Myrogiannis IS, Kellis E. Effects of exercise and an integrated neuromuscular inhibition technique program in the management of chronic mechanical neck pain: a randomized controlled trial. J Manipulative Physiol Ther 2020;43:100-13.

34. Peters D, Chaitow L, Harris G, Morrison S. Integrating complementary therapies in primary care: a practical guide for health professionals. Edinburgh, UK:
Churchill Livingstone; 2002.

35. Mahajan R, Kataria C, Bansal K. Comparative effectiveness of muscle energy technique and static stretching for treatment of subacute mechanical neck pain. Int J Health Rehabil Sci 2012;1:16-21.

36. Speed CA. Extracorporeal shock-wave therapy in the management of chronic soft-tissue conditions. J Bone Joint Surg Br 2004;86:165-71.

37. Ji HM, Kim HJ, Han SJ. Extracorporeal shock wave therapy in myofascial pain syndrome of upper trapezius. Ann Rehabil Med 2012;36:675-80.

38. Hong JO, Park JS, Jeon DG, Yoon WH, Park JH. Extracorporeal shock wave therapy versus trigger point injection in the treatment of myofascial pain syndrome in the quadratus lumborum. Ann Rehabil Med 2017;41:582-8.

39. Rahbar M, Samandarian M, Salekzamani Y, Khamnian Z, Dolatkhah N. Effectiveness of extracorporeal shock wave therapy versus standard care in the treatment of neck and upper back myofascial pain: a single blinded randomized clinical trial. Clin Rehabil 2021;35:102-13.

40. Kamel FH, Basha M, Alsharidah A, Hewidy IM, Ezzat M, Aboelnour NH. Efficacy of extracorporeal shockwave therapy on cervical myofascial pain following neck dissection surgery: a randomized controlled trial. Ann Rehabil Med 2020;44:393-401.

41. Janig W. The sympathetic nervous system in pain: physiology and pathophysiology. In: Stanton-Hicks MD, editor. Pain and the sympathetic nervous system. Boston, MA: Kluwer Academic Publishers; 1990. p. 17 89.

42. Okuyucu EE, Turhanoglu AD, Guntel M, Yilmazer S, Savas N, Mansuroglu A. Does transcutaneous nerve stimulation have effect on sympathetic skin response? J Clin Neurosci 2018;47:160-2.

43. Alghadir AH, Iqbal A, Anwer S, Iqbal ZA, Ahmed H. Efficacy of combination therapies on neck pain and muscle tenderness in male patients with upper trapezius active myofascial trigger points. Biomed Res Int 2020;2020:9361405.

44. Nasb M, Qun X, Ruckmal Withanage C, Lingfeng $\mathrm{X}$, Hong C. Dry cupping, ischemic compression, or their combination for the treatment of trigger points: a pilot randomized trial. J Altern Complement Med 2020;26:44-50. 